\title{
Observed changes in the South Indian Ocean gyre circulation, 1987-2002
}

\author{
Matthew D. Palmer, ${ }^{1}$ Harry L. Bryden, ${ }^{1}$ Joël Hirschi, ${ }^{1}$ and Jochem Marotzke ${ }^{2}$ \\ Received 13 May 2004; accepted 8 July 2004; published 6 August 2004.
}

[1] We use hydrographic data at $32^{\circ} \mathrm{S}$ from 1987,1995 and 2002 to investigate changes in the strength of the subtropical gyre circulation in the Indian Ocean. Relative geostrophic transports are computed for the ocean interior using geopotential anomalies and a zero-velocity surface at $2230 \mathrm{dbar}$ and then filtered with an $8^{\circ}$ Gaussian to remove the high wavenumbers. Our estimates of the relative gyre transports are: $41 \pm 5.1 \mathrm{~Sv}\left(1 \mathrm{~Sv}=10^{6} \mathrm{~m}^{3} \mathrm{~s}^{-1}\right)$ for $1987,42 \pm$ 7.0 Sv for 1995 and $58 \pm 7.0 \mathrm{~Sv}$ for 2002. This represents a $40 \%$ increase from 1987 to 2002 . The main areas of change in the geostrophic transports are just east of Madagascar Ridge and around Broken Plateau, which is consistent with differences we observe in the isopycnal depths in these areas. Maps of contoured velocity suggest that most of the change happened between 1995 and 2002, which supports our transport estimates. INDEX TERMS: 4536 Oceanography: Physical: Hydrography; 4532 Oceanography: Physical: General circulation; 4223 Oceanography: General: Descriptive and regional oceanography; 1635 Global Change: Oceans (4203). Citation: Palmer, M. D., H. L. Bryden, J. Hirschi, and J. Marotzke (2004), Observed changes in the South Indian Ocean gyre circulation, 1987-2002, Geophys. Res. Lett., 31, L15303, doi:10.1029/2004GL020506.

\section{Introduction}

[2] At mid-latitudes the large-scale circulation in the upper $2000 \mathrm{~m}$ of the ocean is characterised by the ocean gyres: a western boundary current and a slower return flow over the ocean interior that must be in approximate mass balance. The gyre transport can be estimated by measuring the density structure of the water column and integrating the geostrophic shear from thermal wind balance. This can be done with a full hydrographic section [Hall and Bryden, 1982] or using measurements near the basin edges and confining the calculation above any intersecting topography [Marotzke et al., 1999]. In both cases one must determine reference level velocities or, equivalently, the barotropic velocity field to obtain absolute transports.

[3] Lavín et al. [1998] estimated the circulation in the subtropical North Atlantic by requiring that the ocean interior transport balance the Gulf Stream transport through the Straits of Florida and the Ekman transport over the Atlantic. Such an approach was largely made possible by cable measurements that measured the total Gulf Stream transport. A similar method has been applied to the Indian

\footnotetext{
${ }^{1}$ School of Ocean and Earth Science, University of Southampton, Southampton Oceanography Centre, European Way, Southampton, UK.

${ }^{2}$ Max Planck Institute for Meteorology, Hamburg, Germany.

Ocean by Bryden and Beal [2001]. Their study used current meter data from 1995 to constrain the mean Agulhas current transport and Lowered Acoustic Doppler Current Profiler (LADCP) data to find the zero-velocity surface across the current.

[4] For the Indian Ocean the temporal variability in the Agulhas Current remains a source of doubt for such transport estimates (H. L. Bryden et al., Structure and transport of the Agulhas Current and its temporal variability, submitted to Journal of Oceanography, 2004; hereinafter referred to as Bryden et al., submitted manuscript, 2004) as does lack of knowledge about the barotropic flow across any hydrographic section. An additional complication is the Indonesian Throughflow (IT), the size of which is poorly constrained by observations [Godfrey, 1996; Sprintall et al., 2002]. It remains unclear how the IT transport is compensated in the southern Indian Ocean. Therefore our analysis concentrates on relative changes in the density structure of the water column over the ocean interior and the associated transports relative to a uniform zero-velocity surface (ZVS).

[5] We present a method for estimating the relative gyre transports over the ocean interior using hydrographic data from 1987, 1995 and 2002 using a uniform ZVS at 2230 dbar. While our analyses focus on the comparison of the two complete hydrographic sections taken in 1987 and 2002 it is useful to include data from the partial occupation of the $32^{\circ} \mathrm{S}$ section in 1995 .

\section{Hydrographic Data}

[6] We use salinity, temperature, and pressure from 2 CTD (Conductivity-Temperature-Depth) sections at nominal latitude of $32^{\circ} \mathrm{S}$ taken in November-December 1987 [Toole and Warren, 1993] and March-April 2002 [Bryden et al., 2003]. A supplementary data set comes from two partial occupations in June-July and March-April of 1995: WOCE sections I5W ([Donohue and Toole, 2003] stations 611:677) and I5E ([Talley and Baringer, 1997], stations 394:442). These three sections generally overlie each other in the west, but deviate east of $80^{\circ} \mathrm{E}$ (Figure 1), following or avoiding a zonal ridge-crest.

[7] Before making any geostrophic transport calculations we examine the density structure for the 1987 and 2002 sections, using sigma-theta $\left(\sigma_{\theta}\right)$ as the density coordinate [Pond and Pickard, 1983]. There are three places where the isopycnals diverge significantly between the two sections (Figure 2): the $\sigma_{\theta}=26.5 \mathrm{~kg} \mathrm{~m}^{-3}$ between $50^{\circ} \mathrm{E}$ and $70^{\circ} \mathrm{E}$; between $600-2200 \mathrm{~m}$ depth, near Madagascar Ridge $\left(45^{\circ} \mathrm{E}\right.$ to $55^{\circ} \mathrm{E}$ ); and at $800-2200 \mathrm{~m}$ depth, near Broken Plateau $\left(85^{\circ} \mathrm{E}\right.$ to $\left.110^{\circ} \mathrm{E}\right)$. There is a particularly striking feature in the 2002 section at about $104^{\circ} \mathrm{E}$, where the station tracks are re-converging at the end of Broken Plateau. These differences suggest that the geostrophic flow field has changed 


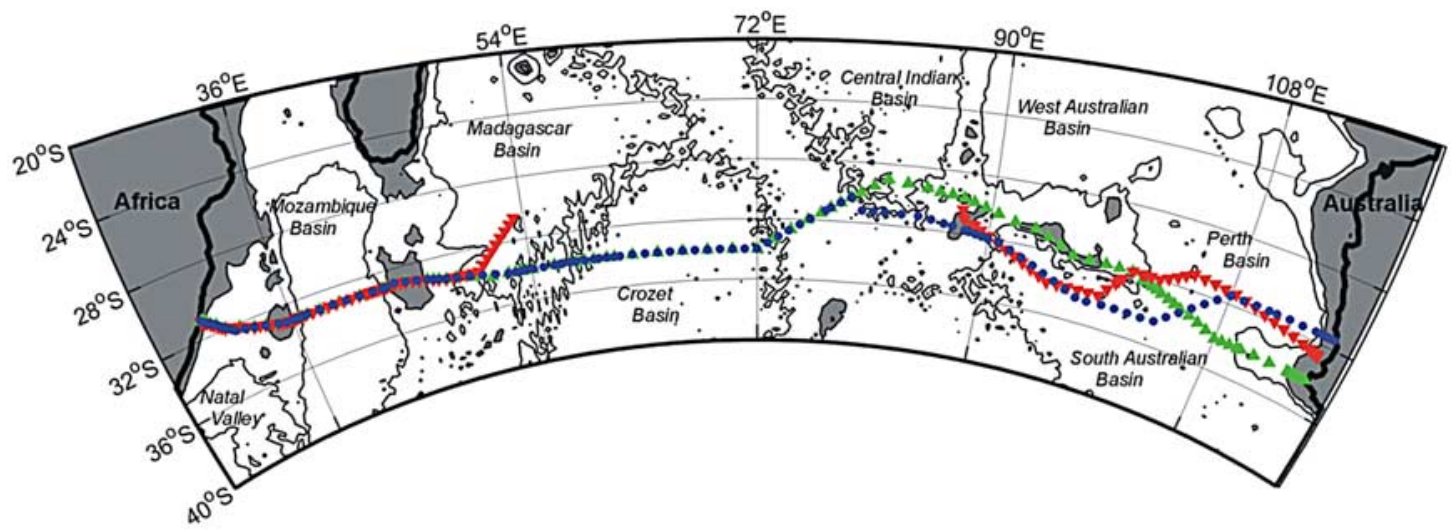

Figure 1. South Indian Ocean bathymetry $(0,2000$, and $4000 \mathrm{~m}$ isobaths, depths shallower than $2000 \mathrm{~m}$ shaded gray) with hydrographic station locations (green triangles, 1987; red triangles, 1995; blue circles, 2002).

between 1987 and 2002. Bryden et al. [2003] and E. L. McDonagh et al. (Decadal changes in the south Indian Ocean, submitted to Journal of Climate, 2004) (hereinafter referred to as McDonagh et al., submitted manuscript, 2004) discuss the changes in water mass properties that occurred between 1987 and 2002 at $32^{\circ} \mathrm{S}$. They report an increase in salinity on potential temperature surfaces for the upper thermocline waters, reversing a trend noted by Bindoff and McDougall [2000] prior to 1987. The observed water mass changes are zonally coherent and do not seem to offer any explanation for the changes in the density field presented here.

\section{Method}

[8] We compute the geostrophic transport between each station pair by calculating geopotential anomaly and integrating upward from a ZVS at 2230 dbar. The ZVS is chosen at a depth of minimum velocity shear in the ocean interior for the 3 sections. Increasing the depth of the ZVS by as much as 800 dbar affects our transport estimates by less than $3 \%$. Where there is topography above the $2230 \mathrm{dbar}$ level, the ZVS is set to the deepest common level of the station pair. This only occurs at the Madagascar Ridge and across Broken Plateau for the 1987 section (Figure 2).

[9] Transports for the upper $2230 \mathrm{dbar}$ are calculated from geostrophic velocities for 1987, 1995 and 2002. Our primary interest is the large-scale flow field, so we low-pass filter the data with a Gaussian of $8^{\circ}$-longitude length-scale to remove the high wavenumbers. The filtering process also allows us to estimate the uncertainty in our transports by computing the standard deviation of the residuals, which we use to estimate the uncertainty due to the eddy and internal wave fields. The estimates of the gyre transport across $32^{\circ} \mathrm{S}$ and changes in the geostrophic flow field among the three sections are discussed in section 4.

[10] We have estimated the error associated with hydrographic sampling on our transports by sub-sampling data from the $1 / 8^{\circ}$ OCCAM global ocean model [Webb et al., 1998] and calculating the geostrophic transports. We found that the sampling induced an uncertainty of $\pm 2.2 \mathrm{~Sv}$ in transport estimates. We estimated a further uncertainty of $\pm 1.7 \mathrm{~Sv}$ associated with sub-annual variations in the geostrophic flow field, based on the $1 / 4^{\circ}$ OCCAM model forced with realistic winds over the period 1993-1999. The model showed no discernable seasonal cycle in the geostrophic transports, so error is treated as random. The uncertainty associated with the eddy and internal wave fields are estimated as $\pm 4.2 \mathrm{~Sv}$ for 1987 and $\pm 6.4 \mathrm{~Sv}$ for 2002. There were not sufficient data to form a reliable estimate for 1995 , so we use the 2002 value. We take the square root of the sum of the three error variances to arrive at uncertainties of $\pm 5.1 \mathrm{~Sv}$ for the 1987 gyre transport, and $\pm 7.0 \mathrm{~Sv}$ for the 1995 and 2002 gyre transports.

\section{Gyre Transports}

[11] The filtered transports above the $2230 \mathrm{dbar}$ ZVS accumulated from west to east (Figure 3) show significant differences among the three sections. The most obvious difference among the three transport curves is the weaker Agulhas transport in 2002 than in 1987 and 1995, which offsets the transport profiles in the vertical. However, we are mainly interested in the northward gyre transport, east of



Figure 2. Contours of density $\left(\sigma_{\theta}\right)$ for 1987 and 2002 (reinforced with black lines). The bathymetry (from left to right) is: Mozambique Plateau, Madagascar Ridge and Broken Plateau. 
about $40^{\circ} \mathrm{E}$ as the Agulhas is known for its large amplitude high frequency variability (Bryden et al., submitted manuscript, 2004 ). From 1987 to 2002 the point of maximum southward transport consistently moves westward, though this change is not significant within our estimated uncertainties. We take our estimate of the gyre strength to be the maximum transport that can be attributed to each curve over the ocean interior, defined as $35^{\circ} \mathrm{E}$ to $110^{\circ} \mathrm{E}$. The transport calculation is made between $55^{\circ} \mathrm{E}$ and $110^{\circ} \mathrm{E}$ for $1987 ; 47^{\circ} \mathrm{E}$ and $110^{\circ} \mathrm{E}$ for 1995 ; and $40^{\circ} \mathrm{E}$ and $110^{\circ} \mathrm{E}$ for 2002 .

[12] The gyre transport estimates are $41 \pm 5.1 \mathrm{~Sv}$ for 1987, $42 \pm 7.0 \mathrm{~Sv}$ for 1995 and $58 \pm 7.0 \mathrm{~Sv}$ for 2002 . Although there are no hydrographic data for 1995 between $52^{\circ} \mathrm{E}$ and $90^{\circ} \mathrm{E}$ the transport estimate is unaffected, because there is no intersecting topography above the ZVS between these longitudes [e.g., Marotzke et al., 1999].

[13] The 2002 data show a large northward transport at about $105^{\circ} \mathrm{E}$ (Figure 3), coincident with a step-like change in the isopycnal depths (Figure 2) over a deep trench in the section bathymetry (not shown). What causes this extraordinary feature is the subject of ongoing research. For the 1995 curve, there is an area of southward transport at about $112^{\circ} \mathrm{E}$ (Figure 3 ), near the Australian coast. This is probably due to the Leeuwin Current, which has its maximum southward velocities in April-May, near the time this part of the section was taken [Feng et al., 2003].

[14] Perhaps the most striking feature of the changes in geostrophic velocity (Figure 4) is the apparent westward migration of the area of southward flow, centred at about $50^{\circ} \mathrm{E}$ in 1987 . The greatest difference between the 1987 and 2002 sections occurs at about $50^{\circ} \mathrm{E}$, where southward flow in 1987 is replaced by northward flow in 2002. This change is consistent with a change from downward sloping isopycnals in the west-east direction in 1987 to upward sloping isopycnals in 2002 in this area (Figure 2). On the western side of Broken Plateau $\left(80^{\circ} \mathrm{E}\right.$ to $\left.90^{\circ} \mathrm{E}\right)$ we see a change from predominantly northward flow in 1987 to southward flow in 2002, which can also be inferred from the differences in slope of the isopycnals in this area (Figure 2). Associated with this change is the intensified northward flow east of

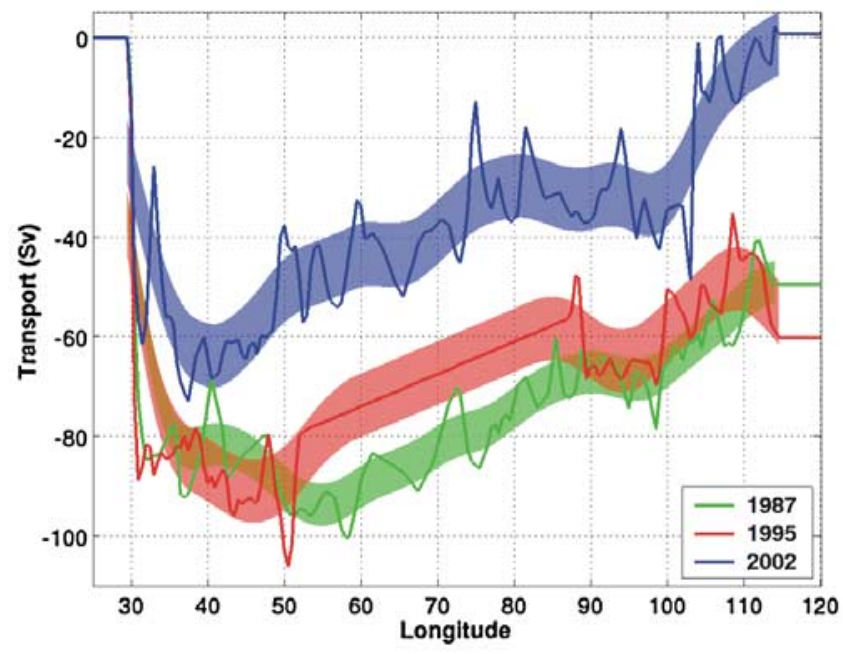

Figure 3. Cumulative transports for 1987, 1995 and 2002 calculated on the station grids (lines) with the corresponding filtered transports at one standard deviation (shaded areas).

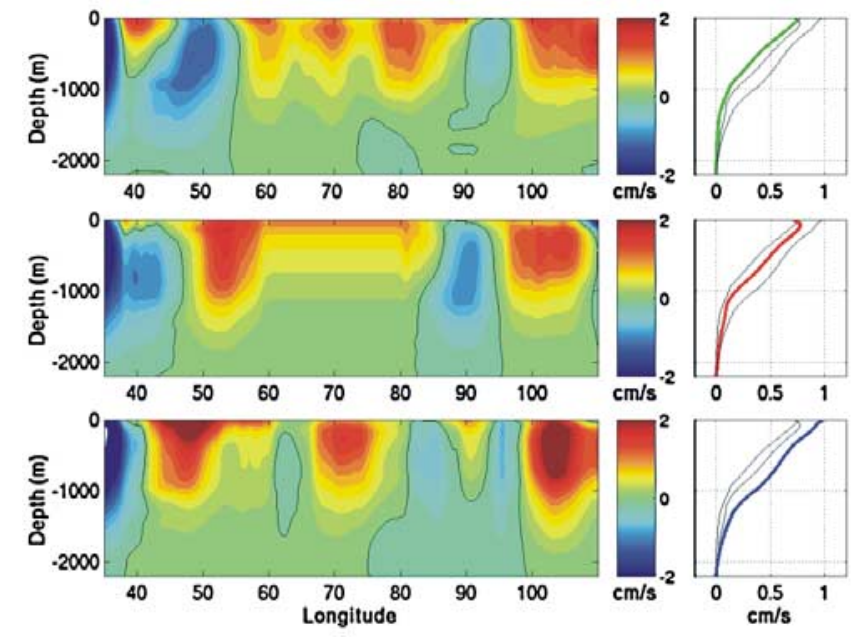

Figure 4. Contours of geostrophic velocity for 1987 (top panel), 1995 (middle panel) and 2002 (bottom panel) after applying an $8^{\circ}$-longitude Gaussian filter (positive values represent northward velocities and zero contours are drawn in black). The panels on the right show the zonally averaged velocity profiles (from $40^{\circ} \mathrm{E}$ to $110^{\circ} \mathrm{E}$ ) for 1987 (green), 1995 (red), and 2002 (blue).

Broken Plateau in 2002, centred on the 'step' in the isopycnals discussed earlier.

[15] The 1995 data give the impression that there has been a persistent change between the flow structure of the 1987 and 2002 sections. The transition can be seen in the zonally averaged velocity profiles (Figure 4), which suggest that as well as differences in the zonal structure of the transports, the gyre has strengthened over the period 1987 to 2002. The northward velocities penetrate to greater depth in 2002 than 1987.

[16] In our comparison of the 1987 and 2002 data sets, we are most confident of our results where the station locations overlie, west of $80^{\circ} \mathrm{E}$. In this region there are clear differences in the geostrophic flow field, mainly in terms of the zonal structure. We recognise that the different station tracks east of $80^{\circ} \mathrm{E}$ and the strong feature in the isopycnals at $104^{\circ} \mathrm{E}$ in 2002 means that our estimates of the relative gyre strengths should be taken with caution.

\section{Conclusions}

[17] We have estimated the size of the gyre transports from hydrographic data using a zero-velocity surface at $2230 \mathrm{dbar}$ for $1987(41 \pm 5.1 \mathrm{~Sv}), 1995$ (42 $\pm 7.0 \mathrm{~Sv})$ and $2002(58 \pm 7.0 \mathrm{~Sv})$. The estimates for 1987 and 1995 are consistent within one standard deviation and the 2002 estimate shows a $40 \%$ increase. The largest uncertainty in these estimates comes from eddy and internal wave noise on the sections. There is a change in the zonal structure of the gyre transports between 1987 and 2002. The principal areas of change are east of Madagascar Ridge and either side of Broken Plateau. The 1995 data suggest that there has been a persistent change in the flow structure over the period 1987 to 2002 .

[18] Bindoff and McDougall [2000] noted a 20\% slowdown of the Indian Ocean gyre circulation between 1962 and 1987 based on transport calculations and changes in 
dissolved oxygen concentrations. The authors also reported a freshening of the upper thermocline waters. In 2002 the upper thermocline waters were found to be saltier on isotherms [Bryden et al., 2003] and dissolved oxygen measurements imply a $20 \%$ speed-up in the gyre since 1987 (McDonagh et al., submitted manuscript, 2004). These findings suggest that there is a link between the water mass changes and gyre strength. The increased gyre strength suggested by McDonagh et al. (submitted manuscript, 2004) is qualitatively consistent with our results, but they observe zonally coherent changes in water mass properties between 1987 and 2002. In contrast, the differences we observe happen in specific areas: just east of Madagascar Ridge and around Broken Plateau in the deep isopycnals and between $50^{\circ} \mathrm{E}$ and $70^{\circ} \mathrm{E}$ in the upper thermocline. The differences in the zonally integrated velocity profiles below $1000 \mathrm{~m}$ (Figure 4) suggest that some of the transport changes between 1987 and 2002 are not related to the shallow water mass changes reported earlier.

[19] Acknowledgments. Thanks to Elaine McDonagh for help with the hydrographic data and to John Stark, Beverley de Cuevas and the OCCAM team for supplying the model data. We would also like to thank three anonymous reviewers for their contribution to improving this paper. This work has been supported by a grant from the Natural Environment Research Council.

\section{References}

Bindoff, N. L., and T. J. McDougall (2000), Decadal changes along an Indian Ocean section at $32^{\circ} \mathrm{S}$ and their interpretation, J. Phys. Oceanogr., 30(6), 1207-1222

Bryden, H. L., and L. M. Beal (2001), Role of the Agulhas Current in Indian Ocean circulation and associated heat and freshwater fluxes, Deep Sea Res., Part I, 48(8), 1821-1845.
Bryden, H. L., E. L. McDonagh, and B. A. King (2003), Changes in ocean water mass properties: Oscillations or trends?, Science, 300(5628), 2086-2088

Donohue, K. A., and J. M. Toole (2003), A near-synoptic survey of the southwest Indian Ocean, Deep Sea Res., Part II, 50(12-13), 1893-1931.

Feng, M., G. Meyers, A. Pearce, and S. Wijffels (2003), Annual and interannual variations of the Leeuwin Current at $32^{\circ} \mathrm{S}, J$. Geophys. Res., 108(C11), 3355, doi:10.1029/2002JC001763.

Godfrey, J. S. (1996), The effect of the Indonesian throughflow on ocean circulation and heat exchange with the atmosphere: A review, J. Geophys. Res., 101(C5), 12,217-12,237.

Hall, M. M., and H. L. Bryden (1982), Direct estimates and mechanisms of ocean heat transport, Deep Sea Res., Part I, 29(3A), 339-359.

Lavín, A., H. L. Bryden, and G. Parrilla (1998), Meridional transport and heat flux variations in the subtropical North Atlantic, Global Atmos. Ocean Syst., 6, 269-293.

Marotzke, J., R. Giering, K. Q. Zhang, D. Stammer, C. Hill, and T. Lee (1999), Construction of the adjoint MIT ocean general circulation model and application to Atlantic heat transport sensitivity, J. Geophys. Res., 104(C12), 29,529-29,547.

Pond, S., and G. L. Pickard (1983), Introductory Dynamical Oceanography, 329 pp., Pergamon, New York.

Sprintall, J., S. Wijffels, T. Chereskin, and N. Bray (2002), The JADE and WOCE I10/IR6 Throughflow sections in the southeast Indian Ocean: 2: Velocity and transports, Deep Sea Res., Part II, 49(7-8), 1363-1389.

Talley, L. D., and M. O. Baringer (1997), Preliminary results from WOCE hydrographic sections at $80^{\circ} \mathrm{E}$ and $32^{\circ} \mathrm{S}$ in the Central Indian Ocean, Geophys. Res. Lett., 24, 2789-2792.

Toole, J. M., and B. A. Warren (1993), A hydrographic section across the subtropical South Indian Ocean, Deep Sea Res., Part II, 40(10), 19732019.

Webb, D. J., B. A. de Cuevas, and A. C. Coward (1998), The first main run of the OCCAM global ocean model, Internal Doc. 34, pp. 1-43, Southampton Oceanogr. Cent., Southampton, England.

H. L. Bryden, J. Hirschi, and M. D. Palmer, School of Ocean and Earth Science, University of Southampton, Southampton Oceanography Centre, European Way, Southampton, S014 3ZH, UK. (mdp1@soc.soton.ac.uk)

J. Marotzke, Max Planck Institute for Meteorology, Bundesstrasse 55, 20146 Hamburg, Germany. 